\title{
Self-Organization of Rotaxane Thin Films into Spatially Correlated Nanostructures: Morphological and Structural Aspects
}

\author{
Jean-François Moulin ${ }^{1}$, Jean Crispin Kengne ${ }^{1}$, Rajendra Kshirsagar ${ }^{1}$, \\ Massimilliano Cavallini ${ }^{1}$, Fabio Biscarini*, \\ Salvador Léon ${ }^{\#, 2}$, Francesco Zerbetto, ${ }^{, 2}$ \\ Giovanni Bottari ${ }^{3}$, and David A. Leigh*,3 \\ ${ }^{1}$ CNR-ISMN- "Nanotechnology of Multifunctional Materials" Research Division, Via P. Gobetti 101, I- \\ 40129 Bologna, Italy, ${ }^{2}$ Dipartimento di Chimica “G. Ciamician”, Università di Bologna, V. F. Selmi 2, \\ 40126 Bologna, Italy, ${ }^{3}$ School of Chemistry, University of Edinburgh, The King's Buildings, West Mains \\ Road, Edinburgh EH9 3JJ, U.K. \\ \#Present address: Department of Chemical Engineering, ETSII / UPM, Jose Gutierrez Abascal, 2, 28006 \\ Madrid, Spain \\ E mail : fabio.biscarini@bo.ismn.cnr.it, francesco.zerbetto@unibo.it, David.Leigh@ed.ac.uk
}

Submitted as supporting material for an article to Journal of the American Chemical Society

\section{Experimental Section}

\section{Materials and thin films}

Thin films of Rotaxane $\mathbf{1}^{1}$ were used. For comparison, thin films of the thread or macrocycle alone were made but they did not give any result. Thin films at different thicknesses ranging from 3 to $35 \mathrm{~nm}$ were spin cast onto different substrates: freshly cleaved highly oriented pyrolitic graphite (HOPG ZYH Grade, NT-MDT, Moscow, Russia) and amorphous carbon films prepared by vacuum sputtering onto freshly cleaved mica.

On either type of substrates, the thin films were deposited by spin casting (1500 rpm) of a solution $(0.5 \mathrm{mg} / \mathrm{ml})$ in acetone (spectroscopic grade, Aldrich) at room temperature. The volume of the solution is $75 \mu \mathrm{L}$, dispensed as a few droplets on graphite substrate 
whose surface was normalized to $25 \mathrm{~mm}^{2}$ area. The samples were then annealed in a thermostatic oven in air at progressively longer times. The annealing temperature was 90 ${ }^{\circ} \mathrm{C}$, which is considerably lower than the melting temperature of rotaxane powder $(>345$ $\left.{ }^{\circ} \mathrm{C}\right)^{1}$. This temperature was chosen because it allows us to control the timescale of experiments. At the end of each time interval, the sample was removed from the thermal bath, quenched to RT, and observed by a microscopy technique. The morphology of the samples remained unchanged for a period of several months.

\section{TEM/SAED experiments}

The annealed films were transferred to copper electron microscopy grids (200 mesh). In the case of the samples deposited on amorphous carbon this transfer was readily performed by a flotation technique ${ }^{2}$. In the case of the samples made on HOPG we had to use a more indirect method to peel off the organic thin film from its substrate that was too thick to be transparent to the electrons. We then evaporated a thin layer of amorphous carbon on top of the film, put small drops of a polyacrylic acid solution (25\% in water, Aldrich) on the zones we wanted to transfer and then peeled these patches after drying 34 hours at room temperature. The polyacrylic acid patches were then put upside down on a distilled water surface and left to dissolve. After 4 hours the self standing carbon film holding the $\mathbf{1}$ crystals stripped from the original HOPG substrate were then picked up on the copper TEM grids.

The samples were observed by bright field electron microscopy and electron diffraction using a Philips CM12 TEM fitted with a LaB6 filament and equipped of a CCD camera (Megaview III from Soft Imaging System). The accelerating voltage was $120 \mathrm{kV}$ and, in order to minimize the beam damage, we used the low dose mode of the microscope 
together with small $\mathrm{C} 2$ aperture (30 micron) and low current (spot 8-9 setting). The selected area electron diffraction patterns were recorded at a $2.50 \mathrm{~m}$ chamber length using a 10 micron selecting aperture. The experiments are carried out at RT on samples prepared in Bologna.

\section{Morphology characterization}

Atomic force microscopy was performed in ambient on the samples prepared on HOPG, and in one case on the sample stripped with amorphous carbon. AFM revealed that films are 5-15 nm thick. AFM scans were performed on the same area on samples annealed for different times, so that the local transformation of the thin film was monitored in the same region. Images have been analyzed using autocorrelation software with the program NIH-Image (NIH, Bethesda, MD).

\section{Modelling}

MM3 model ${ }^{3}$ was used to calculate structure and energy of surfaces of rotaxane 1 . The force field was developed by fitting both heats of formation and structural results in the gas phase and in crystals. All the calculations reported here were performed using the TINKER package ${ }^{4}$. The surface geometries of the rotaxanes were optimized starting from the crystal structure determined by X-ray diffraction data.

(1) Gatti, F. G.; Leigh, D. A.; Nepogodiev, S. A.; Slawin, A. M. Z.; Teat, S. J.; Wong, J. K. Y. J. Am. Chem. Soc., 2001, 123, 5983-5989.

(2) Moulin, J. F.; Brinkmann, M.; Thierry, A.; Wittmann, J. -C. Adv. Mater. 2002, 14, 436-439. 
(3) (a) Allinger, N. L.; Yuh, Y. H.; Lii, J.-H. J. Am. Chem. Soc. 1989, 23, 8551-8566; (b)

Lii, J.-H.; Allinger, N. L. J. Am. Chem. Soc. 1989, 23, 8566-8575; (c) Lii, J.-H.; Allinger, N.L. J. Am. Chem. Soc. 1989, 23, 8576-8582.

(4) (a) Ponder, J. W.; Richards, F. J. Comput. Chem. 1987, 8, 1016-1024; (b) Kundrot, C.; Ponder, J. W.; Richards, F. J. Comput. Chem. 1991, 12, 402-409; (c) Dudek, M. J.; Ponder, J. W. J. Comput. Chem. 1995, 16, 791-816.

\section{Complete references}

(5) (d) Leigh, D.A.; Morales, M. A. F.; Perez, E. M.; Wong, J. K. Y.; Saiz, C. G.; Slawin, A. M. Z.; Carmichael, A. J.; Haddleton, D. M.; Brouwer, A. M.; Buma, W. J.; Wurpel, G. W. H.; Leon, S.; Zerbetto, F. Angew. Chem. Int. Ed. 2005, 44, 3062-3067.

(7) (d) Huang, T. J.; Tseng, H. R.; Sha, L.; Lu, W. X.; Brough, B.; Flood, A. H.; Yu, B. D.; Celestre, P. C.; Chang, J. P.; Stoddart, J. F.; Ho, C. M. Nano Lett. 2004, 4, 20652071.

(7) (f) Jang, S. S.; Jang, Y.H.; Kim, Y. H.; Goddard, W. A.; Flood, A. H.; Laursen, B. W.; Tseng, H. R.; Stoddart, J. F.; Jeppesen, J. O.; Choi, J. W.; Steuerman, D. W.; Delonno, E.; Heath, J. R. J. Am. Chem. Soc. 2005, 127, 1563-1575.

(7) (h) Liu, Y.; Flood, A. H.; Bonvallet, P. A.; Vignon, S. A.; Northrop, B. H.; Tseng, H.-R.; Jeppesen, J. O.; Huang, T. J.; Brough, B.; Baller, M.; Magonov, S.; Solares, S. D.; Goddard, W. A.; Ho, C.-M.; Stoddart, J. F. J. Am. Chem. Soc. 2005, 127, 9745-9759. 